\section{Maternal care and offspring behaviour in three theridiid species (Araneae, Theridiidae)}

Gilbert Barrantes ${ }^{1}$ and Ju Lin Weng ${ }^{2}$

Escuela de Biología, Universidad de Costa Rica, San José Costa Rica

\section{Summary}

Maternal care is widespread in theridiids. Theridion evexum Keyserling breaks the threads in the outer layer of the egg sac to allow its spiderlings to leave the sac. Achaearanea tesselata (Keyserling) and Anelosimus studiosus (Hentz) kill prey for their young spiderlings to feed upon. Occasionally, embryos of $T$. evexum die when their mother fails to break the threads of the egg sac properly, and spiderlings of $A$. tesselata and $A$. studiosus are sometimes killed when they are wrapped along with the prey when the adult spider is attacking prey. Offspring mortality is rare, suggesting that the attack behaviour is highly suppressed in spiderlings of social theridiids.

\section{Introduction}

Parental care is well known to enhance the fitness of offspring (Wilson, 1975; Avilés \& Tufiño, 1998), particularly when species inhabit stressful environments that drastically affect their survivorship (Avilés \& Gelsey, 1998; Miller \& Agnarsson, 2005). In spiders, maternal care is widespread within the family Theridiidae (Avilés, 1997; Agnarsson, 2004, 2006), although the extent of maternal care behaviour varies greatly among genera and even among species in the same genus of this family (Bristowe, 1958; Foelix, 1996; Agnarsson, 2004). It is generally assumed that parental care evolved and is maintained because the benefits outweigh the inherent costs of brood caring (Clutton-Brock, 1991; Bilde et al., 2007). In spiders maternal brood care reduces the female's fecundity and survival (Avilés \& Tufiño, 1998; Bilde et al., 2007). However, at least in some spiders, this cost is outweighed by a greater clutch size and offspring survival which increase the average individual fitness in social spiders (Avilés \& Tufiño, 1998).

Maternal care in some theridiids ceases when the spiderlings emerge from the egg sac (e.g. Latrodectus spp.: Forster \& Forster, 1973), but in social species maternal care includes the cohabitation of spiderlings with their mother for some time (Avilés, 1997; Agnarsson, 2004, 2006). In some social species, in which new webs are established by single females which raise their offspring without the aid of others (Buskirk, 1981; Avilés \& Bukowski, 2006), cohabitation extends until the spiderlings reach the third or fourth instar in the mother's web (e.g. Theridion evexum Keyserling: Barrantes \& Weng, 2007). Even in other species with a more complex social structure, in which colony members cooperate to build and maintain their web, and capture prey cooperatively, members of the colony share brood care (Avilés, 1997; Avilés \& Salazar, 1999; Agnarsson, 2006).

${ }^{1}$ Correspondence author.

${ }^{2}$ Present address: Department of Entomology, Kansas State University, Manhattan, KS 66506, USA.
Maternal care is displayed by theridiids in many different ways, including protecting the egg sac (Bristowe, 1958; Viera et al., 2007), capturing prey for the offspring to feed upon (Bristowe, 1958), regurgitating to the offspring (Bristowe, 1958; Foelix, 1996; Viera et al., 2005, 2007), and accumulating the bodies of dead prey before the emergence of the spiderlings from their egg sac (Barrantes \& Weng, 2007, 2008). Here, we describe the maternal care and offspring behaviours and occasional mortality of offspring associated with maternal care in Theridion evexum, Achaearanea tesselata (Keyserling) and Anelosimus studiosus (Hentz).

\section{Methods}

Observations on the behaviour of adult and juvenile spiders of the three theridiid species were made in captivity, and in the field on the campus of the Universidad de Costa Rica (San José province) and in Parque del Este (Cartago province); both these sites are located at $1100-1300 \mathrm{~m}$ in the eastern portion of the Costa Rican Central Valley. Adult females of $T$. evexum $(n=12)$ and $A$. tesselata $(n=23)$ with their eggs and spiderlings were maintained in captivity as described in Barrantes \& Weng (2006, 2007). The instars were numbered starting with the stage at which the spiderlings emerged from the egg sac ("first instar") (one previous instar occurs within the egg sac), and females become adults possibly at the sixth or seventh instar. Webs with eggs and spiderlings $(n=5)$ of $A$. studiosus were maintained on potted plants; 7 additional webs of adult spiders with egg sacs and/or spiderlings were observed in the field. The behaviour of adults and spiderlings was recorded using a Sony DCR-VX1000 digital camera equipped with close-up lenses; these recordings were complemented with naked-eye observations on captive spiders and in nature. Observations on manipulation of the egg sacs by adult females of $T$. evexum were made daily during the last week before the emergence of the spiderlings from the egg sac. Drawings are based on video images. Specimens of all three species have been deposited at the Museo de Zoología, Universidad de Costa Rica.

\section{Results}

\section{Maternal care}

Theridion evexum: Mature females of this species produced only one or two egg sacs during their life span (unpubl. data). The egg sac was maintained deep inside the retreat that is formed by folding a leaf (Barrantes \& Weng, 2007), and spiderlings emerged approximately 20 days later. Mature females began to store the unconsumed bodies of dead prey about a week before the spiderlings emerged from the egg sac. Spiderlings then fed on both old and newly killed prey (Barrantes \& Weng, 2007, 2008), and they usually remained in their mother's web until their fourth instar outside the egg sac. During this time the adult spider continued to kill prey and to give them to the spiderlings to feed upon ( $n=12$ spiders, $>200$ prey). 


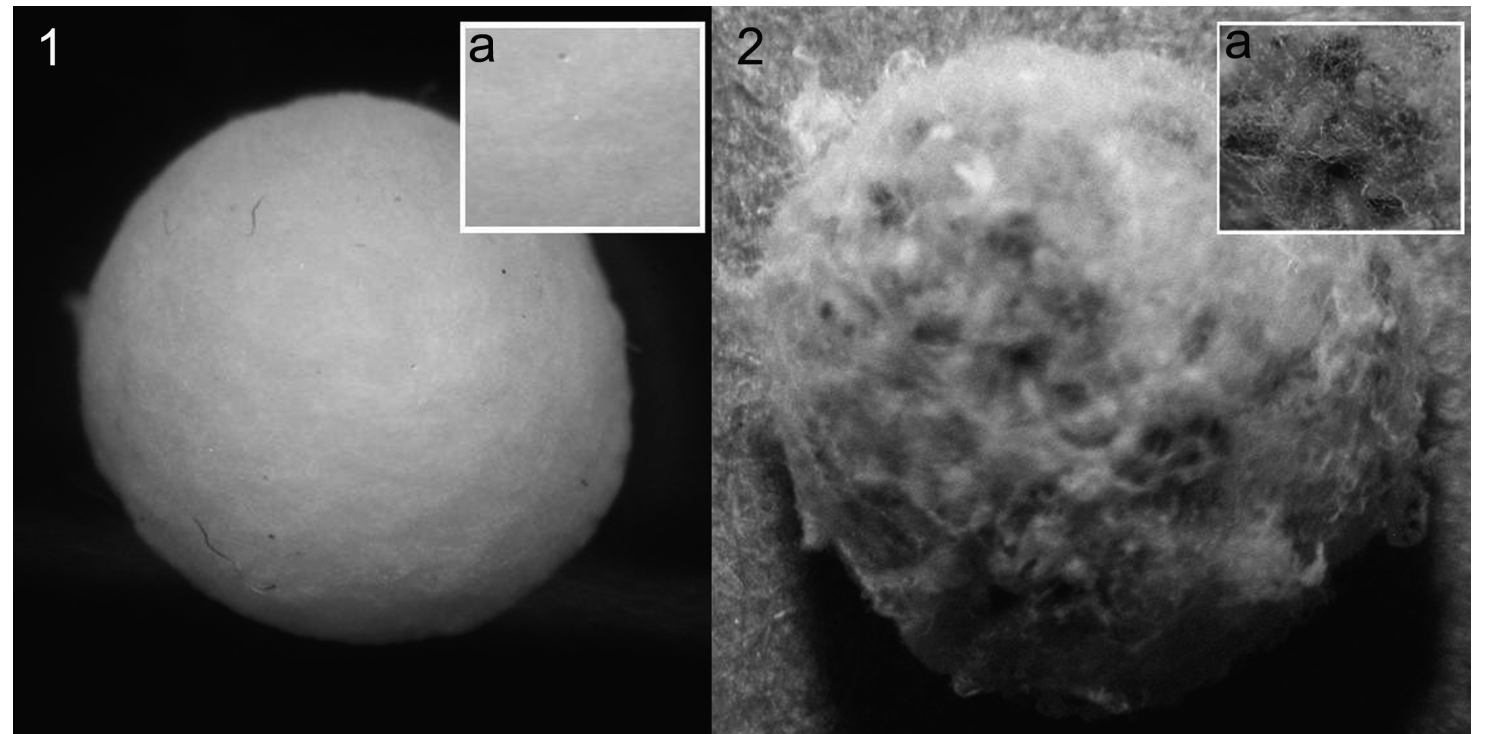

Figs. 1-2: Egg sacs of Theridion evexum. $\mathbf{1}$ Newly spun egg sac, possibly less than a week old; $\mathbf{2}$ Egg sac with the outer layer modified by the adult female. Inset are close ups of the egg sac surface.

In only $5 \%$ of 87 cases in which we followed the adult spider after killing a prey did she feed on the captured prey, usually for only a short period (less than $5 \mathrm{~min}$ ), then the prey was carried to near the retreat, where the spiderlings fed on it. Adult spiders were never observed feeding with spiderlings at the same time. As the spiderlings grew, a few of them occasionally descended to where their mother was attacking a prey, but they did not approach nearer than $2 \mathrm{~cm}$ from their mother. Spiderlings abandoned their mother's web and dispersed in the fourth instar. There was apparently a high mortality of adult females soon after the spiderlings dispersed, as no adult females were found in the population after the highly seasonal burst of reproduction (Barrantes et al., 2008).

The adult female began to break the outer silk layer of the egg sac at least 10 days (possibly more) before the emergence of the spiderlings, and thus facilitated the escape of her offspring. She spent several hours each day pulling on the threads of the outer layer of the sac, particularly during the last days before the spiderlings' emergence. The spider's entire body and the egg sac moved back and forth as she pulled. The spider did not produce a single hole, but rather broke the threads from the entire outer layer of the sac. As a consequence, the appearance of the outer layer of the egg sac changed drastically ( $n>20$, Figs. $1-2)$.

We confirmed that the spiderlings were unable to exit the sac without help from their mother by collecting eight new egg sacs (less than a week old) from different females. The egg sacs were randomly separated into two groups. A $2 \mathrm{~mm}$ diameter hole was made in each egg sac (7-8 $\mathrm{mm}$ in diameter) of one group 25 days later. The egg sacs of the second group were opened completely 40 days after collecting them. All spiderlings emerged from the egg sacs of the first group, but all the spiderlings in the egg sacs of the second group were dead, though they were completely developed. On two occasions (one in captivity and the other in nature) we saw the embryos (larval stage) falling from inside the egg sac as the mature female was breaking the silk threads on the lower surface of the sac; these embryos all died without developing further.

Achaearanea tesselata: This species produced several egg sacs during its life span (range: $2-5$ in the field [ $n=7]$, 8 for one female in captivity), with little (if any) temporal overlap. Consequently spiderlings from different egg sacs did not overlap in their mother's web after emerging. The egg sacs were maintained inside a retreat constructed of debris in the middle of a tangle that the spider constructed above a dense more or less horizontal sheet (Eberhard, 1972). Spiderlings were able to emerge without assistance from their mother from three different egg sacs collected in nature and maintained indoors. The spiderlings stayed in their mother's web until they reached the third instar outside the egg sac, though a

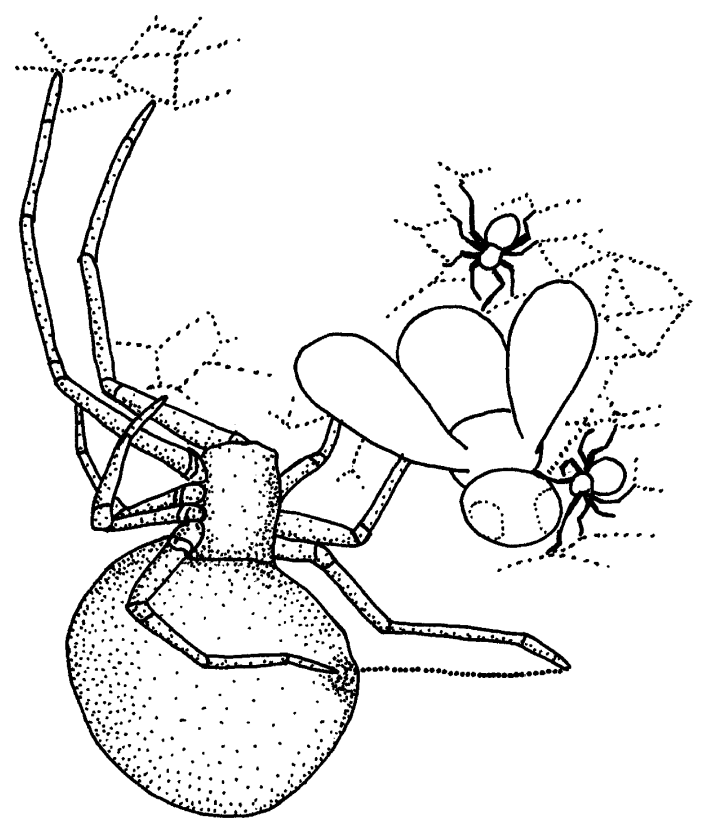

Fig. 3: Adult female of Achaearanea tesselata begins immobilisation wrapping with two young spiderlings dangerously near the prey. 


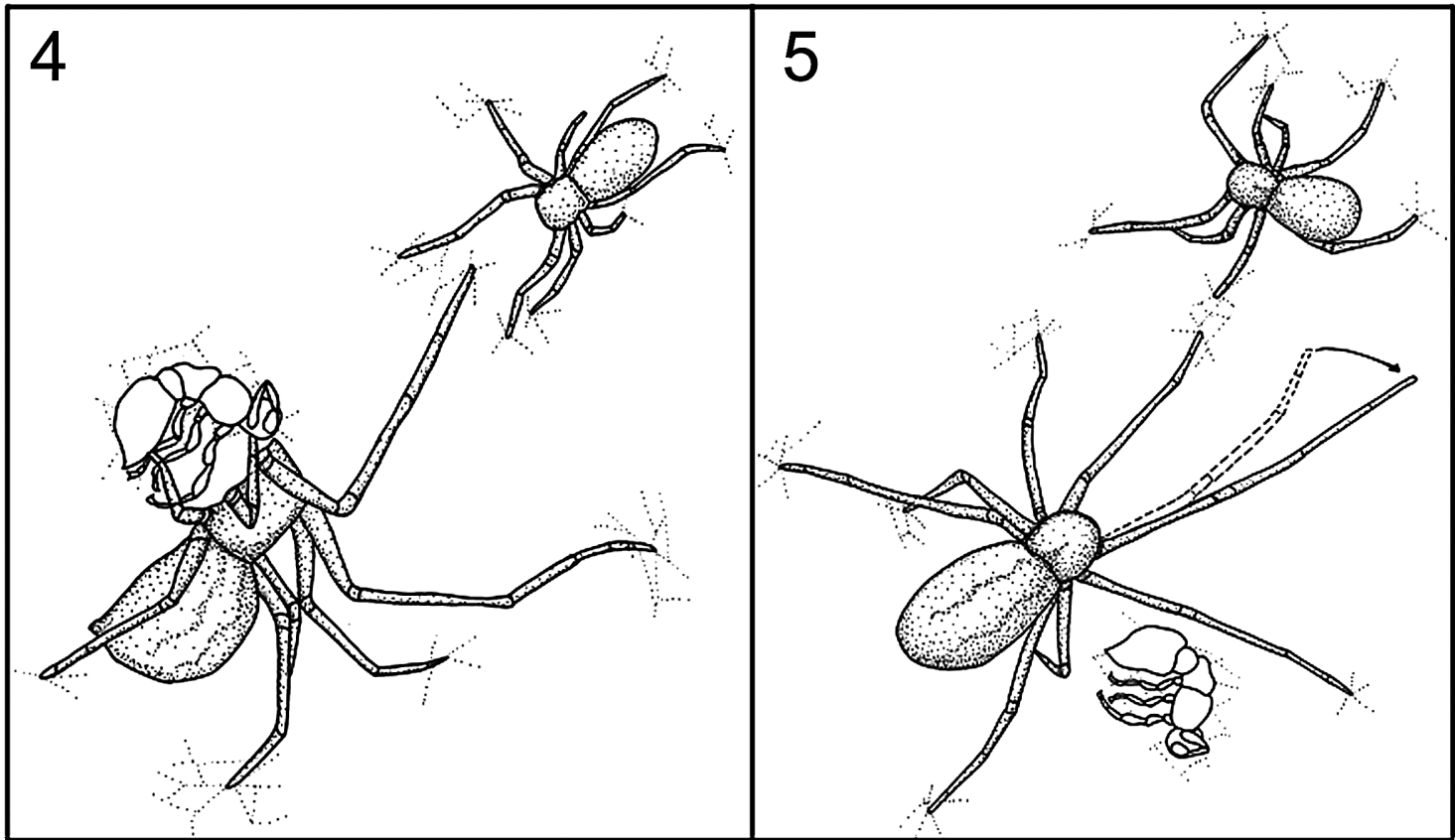

Figs. 4-5: Movements of an adult female and a spiderling of Anelosimus studiosus. 4 Spiderling approaches the adult female while she attacks an ant; 5 Adult female moves towards the spiderling while waving one leg I as the spiderling moves away.

few of them apparently dispersed in the fourth instar. During the entire time that spiderlings stayed in the mother's web, their mother captured prey and hung them in the web for her offspring $(n=16$ spiders, $>200$ prey). In nearly all cases the adult female also fed on the prey she had captured, and she frequently fed at the same time as her spiderlings.

Second and third instar spiderlings occasionally descended to the sheet of the web while their mother was wrapping a prey (Fig. 3), probably stimulated by the movements of the threads during the attack and wrapping immobilisation. The mother tried to prevent the spiderlings from approaching the prey by waving her legs and pushing them away. However, in

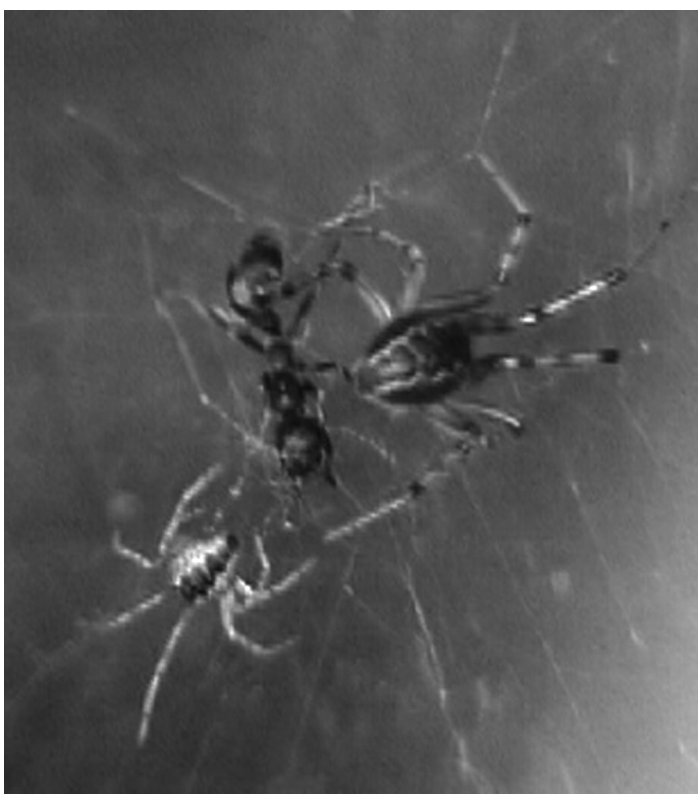

Fig. 6: Adult female and a spiderling of Anelosimus studiosus both wrap an ant. three cases a spiderling got too close to the prey, and was caught in the threads with which the adult spider was wrapping the prey. In all three cases the spiderling was wrapped with the prey in a single package and died.

Anelosimus studiosus: Adult females of this subsocial species produced from one to three egg sacs during their life span $(n=12)$, and only a single adult female was found in a given web. Offspring remained in their mother's web until the third or possibly fourth instar after emerging from the egg sac before dispersing. Third and fourth instar spiderlings often wrapped the same prey that the mother attacked. As spiderlings approached the prey, the adult spider tried to prevent them from getting too close to the prey by waving legs I towards the spiderlings (Figs. 4-5); often the legs I clearly touched the spiderlings. Some spiderlings remained more or less motionless near their mother, but others persisted and moved around the prey to approach it laterally or from the other side, and began to wrap it (Fig. 6). On three occasions ( $n=3$ spiders), a spiderling got caught in its mother's wrapping lines when she fastened the prey to the sheet.

\section{Discussion}

The attack behaviour of spiderlings is greatly reduced in these three subsocial species, since only a small proportion (possibly $<1 \%$ ) of the spiderlings were attracted by the attacking activity of the adult spider. In other solitary species young spiderlings attack readily. For example, first instar spiderlings of Latrodectus geometricus $\mathrm{C}$. L. Koch are capable of dispersing from their mother's web, constructing a web and capturing prey less than a day after emerging from the egg sac (unpublished data). The inhibition of attack behaviour in 
young spiderlings of social species clearly reduces their mortality, thus increasing the fitness of both the spiderlings and their mother. This inhibition may have been important in the evolution of sociality in the family Theridiidae, as have been the reduction in cannibalism and increase in tolerance among spiderlings (Avilés, 1997; Agnarsson, 2006; Agnarsson et al., 2006).

The extensive maternal care shown by $T$. evexum (Barrantes \& Weng, 2008) includes facilitating the escape of the spiderlings from the egg sac. Two aspects of this behaviour are difficult to explain. First, the adult spider removed silk threads from the complete outer layer of the egg sac, but this seems unnecessary as spiderlings can exit the sac through a small hole. Secondly, the spiderlings have apparently completely lost their capacity to open up the egg sac; this has also been reported for $A$. studiosus (Viera et al., 2007). Viera et al. (2007) reported that adult females had to open their egg sacs to allow the emergence of spiderlings, and fed them by regurgitation. On the contrary, spiderlings of some species in the family Lycosidae in which, in nature, the adult female spider cuts open the outer layer of the egg sac when spiderlings are ready to emerge (Gertsch, 1949), can successfully emerge from the egg sac in the absence of their mother (Punzo \& Haines, 2006). Losing the capacity of cutting through the outer layer of the egg sac might give some advantages to the spiderlings of $T$. evexum. The resources used by spiderlings to cut through the outer layer of the egg sac (e.g. enzymes, cheliceral teeth, time) in species in which the mother does not assist spiderlings during emergence, could be redirected to growth or other uses. It is possible that both the assistance of the mother during the emergence of spiderlings and the apparent incapacity of the spiderlings to cut through the outer layer of the egg sac in $T$. evexum and $A$. studiosus are related to the evolution of maternal care and sociality in these species.

\section{Acknowledgements}

We thank William G. Eberhard for his valuable comments on the manuscript and the Vicerrectoría de Investigación de la Universidad de Costa Rica for financial support.

\section{References}

AGNARSSON, I. 2004: Morphological phylogeny of cobweb spiders and their relatives (Araneae, Araneoidea, Theridiidae). Zool. J. Linn. Soc. 141: 447-626.

AGNARSSON, I. 2006: A revision of the New World eximius lineage of Anelosimus (Araneae, Theridiidae) and a phylogenetic analysis using worldwide exemplars. Zool. J. Linn. Soc. 146: $453-$ 593.

AGNARSSON, I., AVILÉS, L., CODDINGTON, J. A. \& MADDISON, W. P. 2006: Sociality in theridiid spiders: repeated origins of an evolutionary dead end. Evolution 60: 2342-2351.
AVILÉS, L. 1997: Causes and consequences of cooperation and permanent-sociality in spiders. In J. C. Choe \& B. J. Crespi (eds), The evolution of social behavior in insects and arachnids: 476-498. New York, Cambridge University Press.

AVILÉS, L. \& BUKOWSKI, T. C. 2006: Group living and inbreeding depression in a subsocial spider. Proc. R. Soc. (B) 273: 157-163.

AVILÉS, L. \& GELSEY, G. 1998: Natal dispersal and demography of a subsocial Anelosimus species and its implications for the evolution of sociality in spiders. Can. J. Zool. 76: 2137-3147.

AVILÉS, L. \& SALAZAR, P. 1999: Notes on the social structure, life cycle, and behavior of Anelosimus rupununi. J. Arachnol. 27: 497-502.

AVILÉS, L. \& TUFIÑO, P. 1998: Colony size and individual fitness in the social spider Anelosimus eximius. Am. Nat. 152: 403-418.

BARRANTES, G., EBERHARD, W. G. \& WENG, J. L. 2008: Seasonal patterns of parasitism of the tropical spiders Theridion evexum (Araneae, Theridiidae) and Allocyclosa bifurca (Araneae, Araneidae) by the wasps Zatypota petronae and Polysphincta gutfreundi (Hymenoptera, Ichneumonidae). Revta Biol. trop. 56: 749-754.

BARRANTES, G. \& WENG, J. L. 2006: The attack behavior of Achaearanea tesselata (Araneae, Theridiidae). J. Arachnol. 34: 456-466.

BARRANTES, G. \& WENG, J. L. 2007: Natural history, courtship, feeding behaviour and parasites of Theridion evexum (Araneae, Theridiidae). Bull. Br. arachnol. Soc. 14: 61-65.

BARRANTES, G. \& WENG, J. L. 2008: Carrion feeding in the cob-web spider Theridion evexum. J. Arachnol. 35: 557-560.

BILDE, T., COATES, K. S., BIRKHOFER, K., BIRD, T., MAKLAKOV, A. A., LUBIN, Y. \& AVILÉS, L. 2007: Survival benefits select for group living in a social spider despite reproductive costs. J. evol. Biol. 20: 2412-2426.

BRISTOWE, W. S. 1958: The world of spiders. London, Collins.

BUSKIRK, R. E. 1981: Sociality in the Arachnida. In H. R. Hermann (ed.), Social insects 2: 281-367. New York, Academic Press.

CLUTTON-BROCK, T. H. 1991: The evolution of parental care. New Jersey, Princeton University Press.

EBERHARD, W. G. 1972: Observations on the biology of Achaearanea tesselata (Araneae: Theridiidae). Psyche, Camb. 79: 209212.

FOELIX, R. F. 1996: Biology of spiders. Oxford, Oxford University Press.

FORSTER, R. \& FORSTER, L. 1973: New Zealand spiders. London, Collins.

GERTSCH, W. J. 1949: American spiders. New Jersey, D. Van Nostrand.

MILLER, J. \& AGNARSSON, I. 2005: A redescription of Chrysso nigriceps (Araneae, Theridiidae) with evidence for maternal care. J. Arachnol. 33: 711-714.

PUNZO, F. \& HAINES, L. 2006: Body size, duration of embryonic development, growth rate, mother-offspring interaction, and diet in Sosippus floridanus Simon (Araneae: Lycosidae). Bull. Br. arachnol. Soc. 13: 365-371.

VIERA, C., GHIONE, S. \& COSTA, F. G. 2005: Regurgitation among penultimate juveniles in the subsocial spider Anelosimus cf. studiosus (Theridiidae): are males favored? J. Arachnol. 34: $258-260$.

VIERA, C., GHIONE, S. \& COSTA, F. G. 2007: Mechanisms underlying egg-sac opening in the subsocial spider Anelosimus cf. studiosus (Araneae, Theridiidae). Ethol. Ecol. Evol. 19: 61-67.

WILSON, E. O. 1975: Sociobiology: the new synthesis. Cambridge, Mass., Harvard University Press. 